Conclusions SSTS has proved an effective and safe device for POP relief after OPCABG. To the best of our knowledge, this is the first report of SSTS use in OPCABG patients.

\section{CONTINUOUS ULTRASOUND-GUIDED RECTUS-SHEATH BLOCK FOR MIDLINE LAPAROTOMY: AN EFFECTIVE POSTOPERATIVE PAIN MANAGEMENT TECHNIQUE - CASE SERIES}

C Pinto, F Matias*. Centro Hospitalar e Universitário de Coimbra, Coimbra, Portugal

\subsection{6/rapm-2021-ESRA.225}

Background and Aims Epidural analgesia, though the gold standard of post-operative pain management for laparotomies, is associated with limitations and is contraindicated in many patients. Continuous rectus sheath (RS) block can provide alternative analgesia after midline laparotomy.

Methods We report 5 cases in which continuous local anesthetic infusion through ultrasound-guided (USG) RS catheters showed effective postoperative pain management for midline laparotomy.The multimodal approach for postoperative analgesia for all 5 patients was: paracetamol $1 \mathrm{~g} 8 / 8 \mathrm{~h}$, ketorolac 30 $\mathrm{mg} 12 / 12 \mathrm{~h}$ or metamizole $2 \mathrm{~g} 8 / 8 \mathrm{~h}$ and ropivacaine $0,2 \%$ through DIB system $(5,2 \mathrm{ml} / \mathrm{h})$ through a bilateral percutaneous USG RS catheter during $72 \mathrm{~h}$. Tramadol $100 \mathrm{mg}$ as rescue analgesia.

Results Patient's pain intensity assessed by numerical rating scale during first $72 \mathrm{~h}$ and the number of times necessary to administer rescue analgesia was also recorded (see table 1). Conclusions With this case series, the authors showed that bilateral percutaneous USG RS catheter as part of a

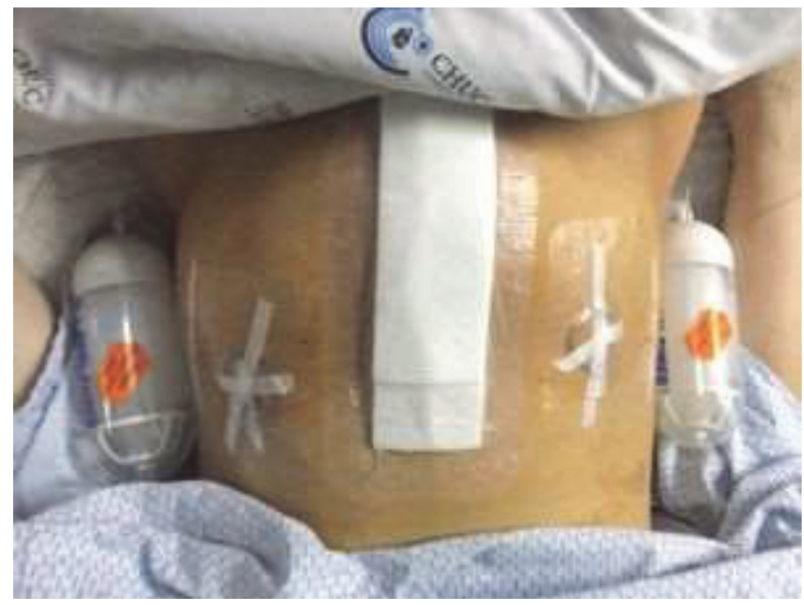

Abstract 225 Figure 1

\section{Abstract 225 Table 1}

\begin{tabular}{|c|c|c|c|c|c|}
\hline $\begin{array}{c}\text { Pain Scores (o- } \\
\text { 10) }\end{array}$ & Care 1 & Cale 2 & $\cos _{3}$ & ches 4 & Cones \\
\hline Worst pain & 4 & 5 & 3 & 3 & 4 \\
\hline Medlum pain & 1 & 1 & 1 & 1 & 1 \\
\hline $\begin{array}{l}\text { Rescue } \\
\text { anslresis }\end{array}$ & & & & & \\
\hline $\begin{array}{c}\text { Administration } \\
\text { times }\end{array}$ & 0 & 1 & 0 & 0 & 2 \\
\hline
\end{tabular}

multimodal analgesia regime seems to provided effective postoperative analgesia for midline laparotomy with minimal or no opioid needs.

\section{USG GUIDED TAP BLOCK FOR POST OPERATIVE ANALGESIA IN CHILDREN WITH COVID INFECTION UNDERGOING LAPAROTOMY}

A Praniarda*. Brawijaya University, Malang, Indonesia

\subsection{6/rapm-2021-ESRA.226}

Background and Aims The COVID-19 infection that broke out in the past year had a major impact on pediatric surgery. The urgency of surgical management and asymptomatic symptom in pediatric patients to the risk of multiorgan inflammatory syndrome makes anesthesiologists consider safe and optimal anesthetic techniques.

Methods 9-year-old with $18 \mathrm{~kg}$ bodyweight was complained of abdominal pain, diagnose with peritonitis and planned for laparotomy. Patients underwent with general anesthesia intubation. Drugs for induction include fentanyl $40 \mathrm{mcg}$, ketamine $20 \mathrm{mg}$, and atracurium $10 \mathrm{mg}$ intravenously. Hemodynamics during surgery was stable and after surgery, the patient performed TAP block of Ropivacaine $0.2 \%$ and Clonidine $30 \mathrm{mcg}$ with total volume $5 \mathrm{ml}$ each side for post operative analgesia. Results Patient was operated in COVID-19 operating room which intubation use aerosol box to prevent aerosol contacted

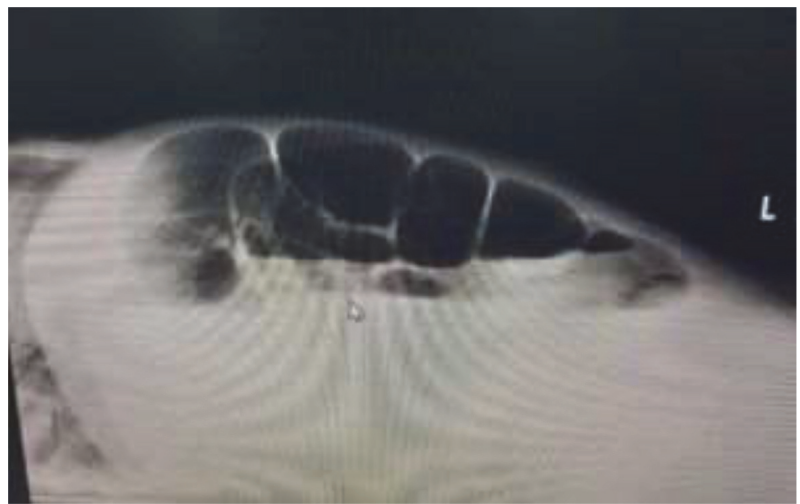

Abstract 226 Figure 1

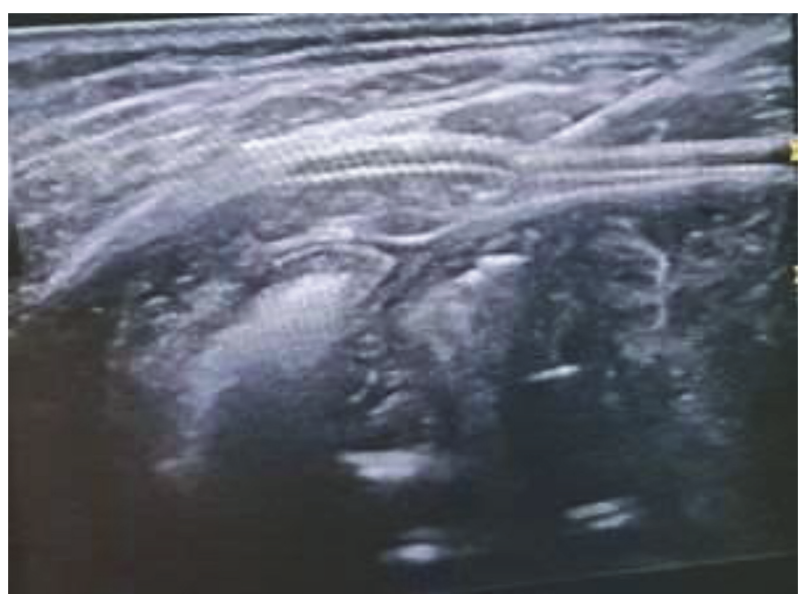

Abstract 226 Figure 2 